\title{
Inferior Dislocation of the Shoulder Complicated with Brachial Plexus Palsy: A Case Report
}

Ghannam Abdelaziz*, Haouzi Mohammed Amine M.D, Fekhaoui Mohamed Reda M.D, Moncef Boufettal Ph. D, Bassir Reda Allah Ph. D, Kharmaz Mohammed Ph. D, Lamrani Moulay Omar Ph. D, Berrada Mohammed Saleh Ph. D

Department of Trauma and Orthopaedic Surgery, Ibn Sina University Hospital, Rabat, Morocco

DOI: $10.36347 /$ sjams.2020.v08i08.011

| Received: 06.08.2020 | Accepted: 13.08.2020 | Published: 19.08.2020

*Corresponding author: Ghannam Abdelaziz

Abstract

Erecta dislocation or lower glenohumeral dislocation is a rare form of shoulder dislocation, Neurovascular complications are particularly common in this type of dislocation due to the significant displacement of the humeral head and the severity of the causal trauma. We report a case of Erecta dislocation complicated by brachial plexus paralysis in a 55-year-old woman managed conservatively. The patient underwent closed reduction under general anesthesia. Neurological Recovery took 10 mounths. At 1 year follow-up the functional result was satisfactory.

Keywords: Shoulder, inferior, dislocation, Brachial plexus.

Copyright @ 2020: This is an open-access article distributed under the terms of the Creative Commons Attribution license which permits unrestricted use, distribution, and reproduction in any medium for non-commercial use (NonCommercial, or CC-BY-NC) provided the original author and source are credited.

\section{INTRODUCTION}

Erecta dislocation or lower glenohumeral dislocation is a rare form of shoulder dislocation, especially in young patients [1]. Neurovascular complications are particularly common in this type of dislocation due to the significant displacement of the humeral head and the severity of the causal trauma.

We report a case of Erecta dislocation complicated by brachial plexus paralysis in a 55-yearold woman with shoulder trauma with a review of the literature highlighting the severity of these injuries.

\section{Case Report}

This is a 55-year-old patient, right-handed with no pathological history, admitted to the emergency room for a closed trauma of the right shoulder following a direct trauma (fall on the shoulder stump) responsible for pain with total functional impotence of the right upper limb.

Clinical examination finds a right shoulder blocked in abduction and supported by the healthy limb. The attempt to mobilize is very painful. The neurovascular exam revealed a loss of sensitivity and motor skills of the entire limb. Conventional radiography edshow a lower glenohumeral dislocation (Erecta) without associated fracture (Figure 1).
The patient was admitted urgently (at $\mathrm{H} 3$ of trauma) to the operating room where a reduction of the dislocation under general anaesthesia was performed followed by immobilization with a postural splint. Postreduction neurological examination showed persistent upper limb paralysis. An X-ray check was performed confirming the reduction of the dislocation (Figure 2).

After 3 weeks, Physiotherapy was started involving passive mobilization of the shoulder, elbow and wrist joints and electrical stimulation.

Electroneuromyography at the 6th objective week post-ganglionic right brachial plexus injury. The physiotherapy was continued with monthly clinical follow-up. At 4 months, the patient had started to recover finger and wrist flexion.

At the 12-month follow-up, the patient had recovered active flexion and extension of the fingers and wrist, and active flexion and extension of the elbow. In the shoulder area, there was still a slight limitation of the range of motion. 


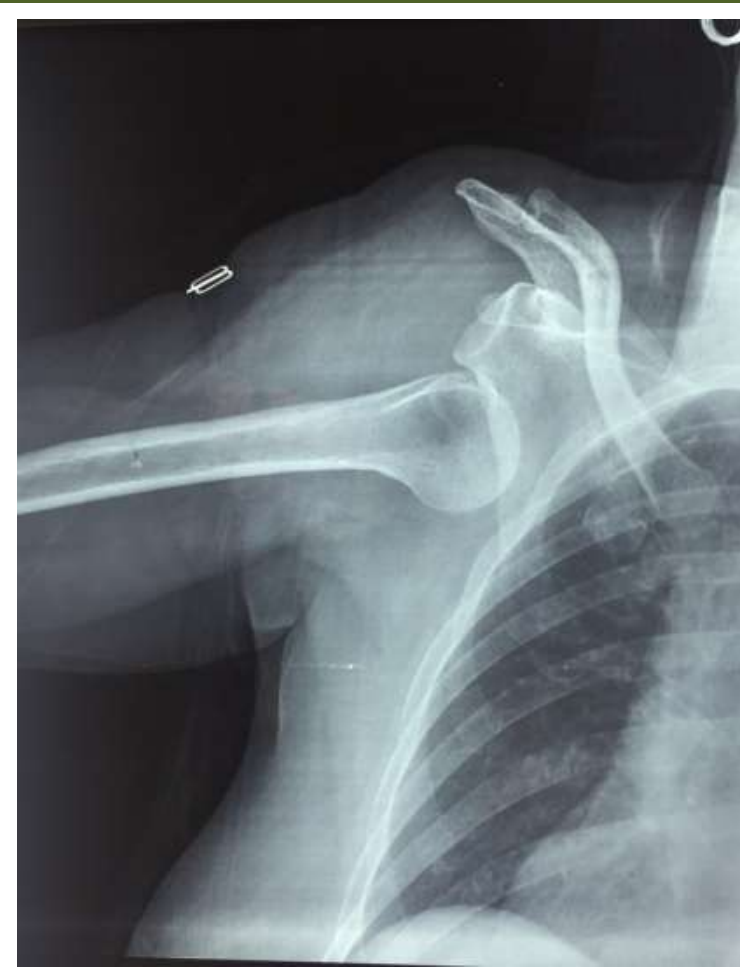

Fig-1: X-ray displaying the inferior dislocation of the shoulder

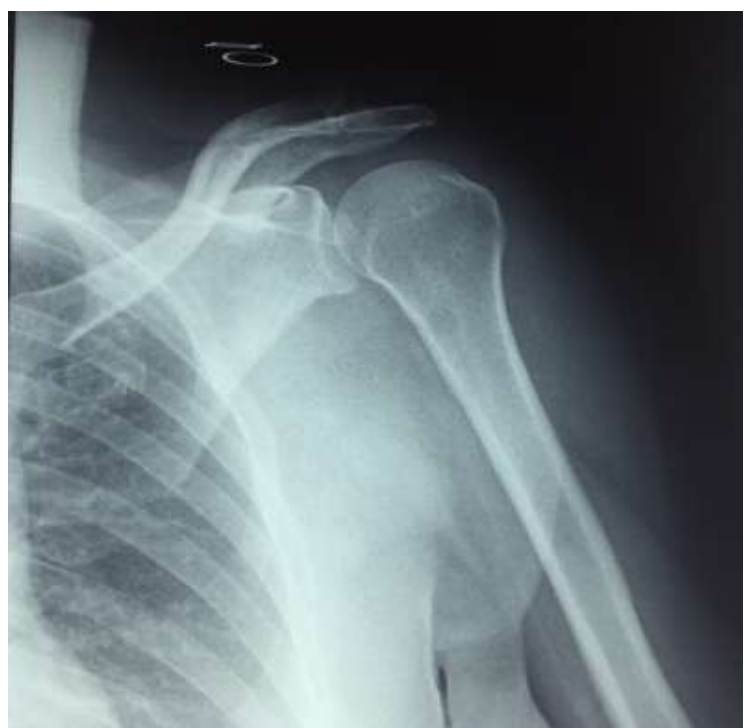

Fig-2: X-ray after the reduction was achieved

\section{DISCUSSION}

Shoulder dislocation in its erecta form is a rare entity, accounting for only $0.5 \%$ of all dislocations in l'épaule $[2,3]$. It is a dislocation of the head in the inferior position. The mechanism is an hyperabduction that brings the humeral neck into contact with the acromion, which serves as a lever for the humerus axis [4]. It is frequently accompanied by severe capsular and labro-ligamentous lesions, which explains the high recurrence rate and the frequent evolution towards chronic instability of the shoulder.
Erecta dislocation is accompanied in about $60 \%$ of cases by damage to the brachial plexus, most often involving the axillary nerve [5], but the lesions may also be combined [6]. They are more likely to occur in people over 50 years of age [7]. In the vast majority of cases, the nerve injury is neurapraxia wich resolves spontaneously after a variable period of time (sometimes 18 months to 2 years) [8].

Electromyography (EMG) is not indicated immediately and follow-up is clinical only. If the neurological disorders persist at 6 weeks after the trauma, an EMG test is indicated [9]. There is no indication for emergency surgical exploration, as most lesions have a good prognosis and evolve favourably towards complete recovery, first sensory and then motor [10].

The absence of clinical or electrophysiological evidence of recovery beyond 3 to 6 months justifient surgical exploration for neurolysis, and possibly direct nerve repair, nerve grafting or nerve transfer (neurotization) [11]. Early intervention is extremely important in obtaining a good result. The optimal time of nerve reconstruction is regarded as 3 to 6 months after injury [12]. Palliative surgery is indicated when the time limits for nerve surgery are exceeded or after failure of the surgery. The objective is to restore or improve the function of the elbow, but also of the shoulder and hand through various surgical procedures : tendon transfers, arthrodesis and tenodesis [13].

\section{CONCLUSION}

Erecta dislocation is a rare entity with frequent neurological complications requiring careful neurological examination before and after reduction. The prognosis is generally favourable. Spontaneous recovery is the rule.

\section{REFERENCES}

1. Groh GI, Wirth MA, Rockwood Jr CA. Results of treatment of luxatio erecta (inferior shoulder dislocation). Journal of shoulder and elbow surgery. 2010 Apr 1;19(3):423-6.

2. Tsuchiday T, Yaney K, Kimura Y. Luxation event of bilateral shoulders. J Shoulder Elbow Surg. 2001 ;10(1) :595-7.

3. Yamamoto T, Yoshiya S, Kurosaka M, Nagira K, Nabeshima Y. Luxatio erecta (inferior dislocation of the shoulder): a report of 5 cases and a review of the literature. American Journal of Orthopedics (Belle Mead, NJ). 2003 Dec 1;32(12):601-3.

4. Dahmi FZ, Moujtahid M, El Andaloussi Y, Bekkali Y, Zaouari T, Nechad M, Ouarab M. Luxation erecta de l'épaule (à propos de huit cas). Chirurgie de la main. 2008 Sep 1;27(4):167-70.

5. Yanturali S, Aksay E, Holliman CJ, Duman O, Ozen YK. Luxatio erecta: clinical presentation and management in the emergency department. The 
Journal of emergency medicine. $2005 \mathrm{Jul}$ 1;29(1):85-9.

6. Atef A, El-Tantawy A, Gad H, Hefeda M. Prevalence of associated injuries after anterior shoulder dislocation: a prospective study. International orthopaedics. 2016 Mar 1;40(3):51924.

7. Pasila M, Jaroma H, Kiviluoto O, Sundholm A. Early complications of primary shoulder dislocations. Acta Orthop Scand. 1978; 49:260263.

8. Oberlin C, Belkheyar Z, Durand S. Paralysies traumatiques du plexus brachial de l'adulte par lésions radiculaires. EMC-Appareil locomoteur. 2007;2(2):1-1.

9. Öztürk M, Cunningham G, Holzer N. Prise en charge d'un premier épisode de luxation antéroinférieure de l'épaule chez l'athlète. Rev Med Suisse. 2018; 14: 1326-1331
10. Saab M. Brachial plexus lesion following an anterior dislocation of the shoulder. European Journal of Emergency Medicine. 2004 Jun $1 ; 11(3): 168-9$.

11. Ameh V, Crane S. Nerve injury following shoulder dislocation: the emergency physician's perspective. European Journal of Emergency Medicine. 2006 Aug 1;13(4):233-5.

12. Mamane W, Masmejean E. Paralysie traumatique $\mathrm{du}$ plexus brachial de l'adulte: Prise en charge chirurgicale initiale. InPlexus brachial Actualités et perspectives 2012 (pp. 17-26). Springer, Paris.

13. Valenti P, Kilinc A. Chirurgie palliative dans les séquelles de lésions du plexus brachial chez l'adulte. InPlexus brachial Actualités et perspectives 2012 (pp. 33-40). Springer, Paris.

14. HR Park, GS. Lee, IS. Kim, JC. Chang. Brachial Plexus Injury in Adults The Nerve. 2017; 3(1) : 111. 